\title{
Wilhelm Dilthey: Understanding the Human World
}

\author{
Iryna Liashenko
}

\author{
$\mathrm{PhD}$, Associate Professor, Taras Shevchenko National University of Kyiv (Kyiv, Ukraine) \\ E-mail: irina_lyashenko@univ.net.ua \\ ORCID: 0000-0003-3912-2075
}

\begin{abstract}
This article has the same name as the second volume in a six-volume translation of the major writings of Wilhelm Dilthey, published in Princeton University Press in 1991-1996, for two reasons: 1) to limit our research of key philosophical and psychological writings from the 1890-s, in which Dilthey propagated a descriptive and analytic psychology as a "human science" (Geisteswissenschaft); 2) to emphasize and understand Dilthey's assertion that the human world was sufficiently different from the natural world that special methods were required for its study; hermeneutics, the deliberate and systematic methodology of interpretation, was the only necessary approach for studying and understanding the human world.

Keywords: Wilhelm Dilthey, understanding, hermeneutics, human world, psychology, human science, Plato's Line
\end{abstract}

Received 30 May 2017; accepted 29 June 2017

Philosophy and Cosmology, Volume 20, 2018: 163-169

DOI: $10.29202 /$ phil-cosm/20/16

\section{Introduction}

The terminology question of this or that philosopher, to which the historian-philosopher proceeds via the consideration of the doctrine or certain ideas, is not of second-rate importance; in some cases, it becomes a very important one. The latter is related to the work of Wilhelm Dilthey, who is "... best known for the way he distinguished between the natural and human sciences" [Makkreel, 2016]. In our view, Dilthey did not concern himself about strictness and transparency of his own terminology, therefore, in order to understand his texts and ideas contained in them, one must always keep in mind the peculiarities of his terminology. In this regard, Vladimir Bibikhin noted: "One can stop reading through the text just in those places that seem to be intelligible" [Bibikhin, 2001: 522].

Dilthey did not overuse new terms and, as compared, for example, to Edmund Husserl or Martin Heidegger, might seem to have almost a conservative character, because he strong disliked terminological innovation. Concerning the terminology of Dilthey's concept about a descriptive and analytic psychology, Heidegger rightly remarked: "These provisions are set out in rude, primitive way of traditional psychology" [Heidegger, 1998: 128], that is, they are enshrined in the terminology through empirical and naturalistic psychology, which Dilthey was trying to overcome.

(C) Liashenko, Iryna, 2018 
It is difficult to argue with Heidegger himself, who knew Dilthey's works well, but in our view, in Dilthey's "traditional" terms, a non-traditional meaning is often hidden. This applies not only to auxiliary or secondary concepts, but also to basic ones, such as: an experience that differs significantly from Kant's prototype; objective spirit whose meaning is not identical to the meanings put into this concept by Hegel; the conceptual triad of experience, expression and understanding that Dilthey borrowed from Johann Droysen; etc. All these identical and "traditional" terms conceal in themselves, in fact, different meanings.

Conceptual clarity is often difficult to trace even in those concepts of metaphor that Dilthey uses in the titles of his main works. For example, in the title "The Construction of the Historical World in the Sciences of the Spirit," the term-metaphor (the metaphor-term) "construction," as it later turns out from the text, is ambivalent. Under the "construction," Dilthey simultaneously understands: as disarticulation of the structure, which is characterised by the interconnection of the historical world, and as metaphoricity, and not the strictness of the term.

\section{Understanding the Human World, as a period in Dilthey's philosophy}

Understanding the Human World, as a period in Dilthey's philosophy, is noteworthy because it characterises Dilthey as a representative of Plato's Line, to which Oleg Bazaluk relates the philosophers, whose teachings had a significant influence on the development of the history of world culture [Bazaluk, 2017]. This can be seen clearly from an expansive view of philosophy as one of "...establishing integral relations to all the theoretical disciplines and historical practices that attempt to make sense of the world" [Makkreel, 2016]. This allowed Dilthey to consider the human spirit in general, at the scale of the Kantian rigor and Fichte's and Hegel's idealism.

Dilthey conceived the human sciences as understanding the meaning of human action and interaction. This is considered in the major works of this period: "Ideas for a Descriptive and Analytic Psychology" ("Ideen über eine beschreibende und zergliedernde Psychologie") of 1894 and "The Origin of Our Belief in the Reality of the External World and Its Justification" ("Beiträge zur Lösung der Frage vom Ursprung unseres Glaubens an die Realität der Aussenwelt und ihrem Recht") of 1890 [Dilthey, 1924]. Dilthey considers psychology a foundational human science only if it is descriptive. Deepening the tradition of Plato's Line, Dilthey claims that only a multidisciplinary approach to human history turns Individual human beings from the monadic building blocks of history into points of intersection. As conscious living beings, individuals are the carriers of history, but they are just as much the products of history [Makkreel, 2016]. Therefore, Dilthey considers the human sciences as analysing human interactions at a level that can mediate between individual initiative and communal tradition.

\section{Understanding as structural articulation}

"Life experience," according to Dilthey, arises as a result of observations on life. As human nature always remains the same, so life experience with its basic features is something common to all. Dilthey believes that it is in human that the philosophy should seek "the inner connection of its knowledge." Human's life must be got to know, firstly, through the unity of vital relations and an experience based on them; secondly, through the direction of one's attention on understanding, being replete with life's contradictions (vitality and regularity, reason and arbitrariness, clarity and mystery); thirdly, assuming that the image of life is represented by evolving fragments of life experience. 
For this reason, Dilthey emphasises the important role of the idea (the principle) of development for understanding life, its manifestations and historical forms. He noted that the doctrine of development is necessarily linked to the cognition of the relativity proper to the historical life form. In the face of the whole history and all past events, the absolute validity of any particular form of life disappears.

The methodology of positivism is known: the goals of culture, like other objects of perception, are first reduced to its simplest elements so that they can later be represented not as accidental, but as having received the logical form of a certain philosophical project. Here, the scientific status of psychology is revealed, according to which it became the basis of any theory of cognition because the principle of representation made us seek the sources of mental procedures in the peculiarities of the individual's mental structure. Dilthey put forward the thesis that if explanative psychology can be the basis in the natural sciences, then the sciences of the spirit need the so-called "descriptive" psychology. The method of the first science is an explanation of the already known primary elements; the method of the second science is a direct search for the connection to experiences.

Descriptive psychology considers mental phenomena in fixed descriptive terms that allow one to interpret human life and experience in a similar manner to text. Just as the structure of text builds up its unity out of its own center, so the structure of life is determined by fixed parts of the continuously differentiated continuum of psychic life.

Thus, Dilthey tried to revise the basis of European philosophising - the idea of the world as representation, whose dominance gave rise to the theories of cognition, as the means of ascent to wholeness (totality). If a human did not create nature, and it was given to him as a kind of the experience, as something partial, so the movement toward fixation seemed justified enough for Dilthey. In the field of the sciences of the spirit, Dilthey proposed an inverse procedure: to proceed from the presence of the whole, but not from parts, because a human makes his world himself, and in the traditions of European philosophizing, the mind that observes is identical with the mind that creates. Therefore, only that what is created by human can be cognized not as a partial, but as a whole. Moreover, if the life of nature can only be learned, the life of culture is already given in its various forms. In other words, when human begins to learn nature, he is already conditioned by certain forms of social life, which set the direction for the goals, interests and ways of knowing reality. For Dilthey "... the sciences of the spirit were not a special "point of view" on reality, but reality themselves, a part of its content, as he himself said" [Shpet, 1995: 16]. Therefore, only an understanding of the structure, concrete historical content of the social world, makes it possible to understand the life of ideas and the reasons for the existence of certain "points of view."

A multidisciplinary approach to human history allowed Dilthey to use a new structural approach - understanding as structural articulation. Dilthey developed the basis of a Descriptive and Analytical Psychology, which differed from traditional explanative psychologies in that they considered psychic life as the continuously differentiated continuum, which produces the individuation of human life. Understanding yourself and the importance of your individual life comes only "through a comparison of myself with others" [Dilthey, 1924].

\section{Dilthey's principle of understanding life}

To understand life, Dilthey introduces categories as ways of comprehending it, contrasting them with the Kantian method: “...these categories are not a priori with regard to life as something alien but deeply rooted in the essence of life itself" [Dilthey, 1995: 132]. He also calls them "real categories" in contrast to "formal" ones. It is necessary to explain: if a de- 
scriptive psychology is a reflection of reality, then Dilthey category of "life" is analogous to Schopenhauer's "will" - both the first and second are the origin. However, "will" manifests a spontaneous beginning, and "life" reflects temporality, as a fundamental condition of human existence; as a condition for linking fragments of reality, because it creates itself thanks to its own internal resources.

The source of connectedness of life is contained in the structure of inner psychic life, which is expedient, since all the parts: will, desire, imagination, etc. are used to achieve the vital task. In Dilthey's view, the "significance of life" arises from the category of "value," without which only a causal connection could be formed. Values arise due to collisions with a variety of things in the surrounding world, generating its own state of pleasure or suffering, respectively - the desire or prevention of certain things. Values determine goals and movement towards their achievement. At this stage, we need such actions as an assessment of our own abilities and possibilities, as well as an analysis of conditions that facilitate or prevent our goal achievement. An analysis of such conditions can be called the understanding of "historical conditioning". Historical conditioning demonstrates the connection of the past, as an aspect of conditioning; the present, as a situation that gives rise to a problem; and the future, as a goal that can solve the problem. Therefore, for understanding and realization of life, the category of "significance" becomes one of the main ones. The significance is not only that which causes further events; otherwise, it would be a cause-and-effect connection, not a teleological one. A significant moment is important for the formation of the whole, for example, an experience can be considered as significant.

In the temporal aspects, life is formed in the process of the influence of the external environment on the organism and the reciprocal organism reaction to this influence in the modes of subordination and conquest. In this respect, the category of "development" is defining, as the unfolding process of individual life, and not in the sense of subordinating the world goal. The essence of development lies in the formation of character. In this regard, Hans-Georg Gadamer wrote: "What emerges, the actual "individuality" - i.e., the character of the individual - is not a mere consequence of the causal factors nor to be understood only in terms of these causes, but it constitutes a unity that is intelligible in itself, a unity of life" [Gadamer, 1988: 275].

Another important stage to understanding of the historical life form was the awareness that all the differences manifested themselves in direct experience and were created by a culture within which human was. Will, perception, thinking, imagination, desire are all different differentiations of a single cultural continuum. The totality of thoughts contained within our minds is also a concrete historical product. Talk about the origin of ideas means to refer not to pure reason, but to the past, to culture, as a product of historical changes. Therefore, the program of life takes place under the influence of concrete historical circumstances. In order to know yourself or others, it is possible only through the knowledge of the culture in which human is developing. "It is precisely the possibility of a biography, drawn up on the basis of the scientific method: an individual does not oppose the infinite game in the historical world; on the contrary, the sphere of his life - the state, religion, science, in short, his own system or the interconnection of his life" [Dilthey, 1995: 141].

In fact, human knows himself only in history, never through introspection; indeed, we all seek him in history... Human is only given to us at all in terms of his realized possibilities... His life is historically determined and possible only in this way. A human can live only within a historically specific culture. Only within it, he can find his purpose. Thus, a human is defined by the relation between individuality and objective spirit or forms of culture [Dilthey, 1995: 143]. 
Therefore, there is a problem in Dilthey's thinking: a descriptive psychology had to be the foundation of the sciences of the spirit, but the researcher's definitive conclusion was the proclamation of the value of individuality. Dilthey's desire to avoid the traps of European metaphysics made him seek a philosophical foundation for the idea of life, which subsequently contributed to the reduction of life to the standard of living of an individual. The project of justification of the sciences of the spirit also regarded an individual as one whole embodiment of historicity.

\section{Human and History}

Psychic life is given as primary and fundamental, therefore its understanding, as a continuously differentiated continuum, makes it possible to understand the human world.

In Dilthey's view, human and history are not different concepts. Human is a historical being, made to live and discover himself through history, in which human's essence is considered. One of the tasks of a descriptive and analytic psychology, as Dilthey sees, is to show that the individuation of human life is born from the continuously differentiated continuum of psychic life. Dilthey believes that an individuality is not a set of individual qualities or traits, which every human is endowed with since his birth. In Dilthey's view, an individuality is an experience that each of us acquires historically. This experience distinguishes people from each other and completely differently develops individual qualities. The human world is understood as a structural configuration of a set of dominant qualities, formed under the influence of historical events. Hence, the understanding of history gives the possibility to understand the human world. Therefore, the sciences of the spirit, in order to understand the human world, must first come from the very method of understanding - immediate comprehension and achievement of a certain spiritual integrity. This is tantamount to penetrate into the spiritual world; it is essentially the reconstruction of the cultural context that created the individual spiritual world. In relation to the culture of the past, understanding is considered as a method of interpretation (hermeneutics) that is the art of understanding of the various objectified manifestations of life. Dilthey defined understanding as "the process by which we know some inner content from signs received by the senses from outside," and interpretation was for him "the artistic understanding of life manifestations objectified in written form" [Dilthey, 2010]. He conceived hermeneutics as being "the methodology or art of understanding recorded expressions" and as the methodological basis of all humanitarian knowledge. In one of his works, Mark Tappan summarizes Dilthey's vision of hermeneutics and considers his conception of the so-called hermeneutic circle, which characterizes the complex dynamics involved in the process of interpretation [Tappan, 1997].

Dilthey differentiated two types of understanding, the understanding of systems, that is the objects in a lifeworld and the lifeworld as a whole and the understanding of the life expressions of others. Dilthey considered the ability to empathy as a condition for the possibility of understanding cultural and historical reality. The particularly "strong form" of understanding of life, according to Dilthey, is art, because it is connected with experience and simultaneously with the understanding of a certain event.

Dilthey introduced the philosophical thesis about the nature of humanitarian knowledge for scientific use as a consequence of the fullness of human life, which is realized in the interrelation between goals and interests. The discovery of the interlinking between an individual and the constellation of ideas, texts, personalities, events, which create his own world was a purpose of Dilthey's theoretical concept that was realized in historical studies [Plotnikov, 2000: 51]. 
Every human bears within him his own direct experience of his states. The experiencing individual can focus on himself and try to understand himself because he understands his states. The other cannot do it, so he needs a special procedure of understanding and interpretation. Hence, historical research requires not only the establishment of a specific goal as the cause of an event but also the search for a motive. Dilthey represents the life process as the as a stream of individualities. If an individual's emotional state is obvious, then it might be caused by the historic event. Unlike many historians of philosophy, Dilthey argued for the importance of "details," "small details," "second place," which could explain much in any historical event. Dilthey did not create the completed philosophical teaching but showed how from "details" of the cultural context, it emerged. Dilthey proved that beneath the surface of the event there was always a hidden motive. Therefore, to understand means not to get experience, referring to events that occurred in the past, but to discover the motives that prompted the historical personality to take certain actions.

\section{Conclusion}

We have briefly reviewed the period in the work of Wilhelm Dilthey and called "Understanding the Human World," which is important in the history of culture for several reasons:

1. It characterizes Dilthey as a representative of Plato's Line, to which Oleg Bazaluk relates the philosophers, whose teachings had a significant influence on the development of the history of world culture [Bazaluk, 2017].

2. It was an important stage in the development of hermeneutics, the deliberate and systematic methodology of interpretation, which was the only necessary approach for studying and understanding the human world. Through Dilthey's work, it became possible not only for the emergence of psycholinguistics but also for the achievement of the level that is considered in Lidija Krotenko's article: the possibilities of psycholinguistics in the identification and interpretation of languages and texts of Alien Civilizations [Krotenko, 2017].

\section{[Dd References}

Bazaluk, Oleg. The Strategies of Systematization of the Theories of Education. The Main Meaning and Features of the Theories of Education of Plato's and Isocrates' Lines. Future Human Image. 7, 2017: 11-27.

Bibikhin, Vladimir. Hermeneutics and Aesthetics in Dilthey's Work. In 6 volumes: Volume 4. Moscow: Dom intellektualnoy knigi, 2001.

Dilthey, Wilhelm. Die Jugendgeschichte Hegels. Berlin, 1905.

Dilthey, Wilhelm. Categories of Life. Voprosy Filosofii. 10, 1995: 129-143.

Dilthey, Wilhelm. Selected Works, Volume II: Understanding the Human World. Edited with Introduction by Rudolf A. Makkreel and Frithjof Rodi. Princeton University Press, 2010.

Dilthey, Wilhelm. Ideen über eine beschreibende und zergliedernde Psychologie. From Wilhelm Dilthey's Gesammelte Schriften, V. Bd: Die geistige Welt. Einleitung in die Philosophie des Lebens. Erste Hälfte: Abhandlungen zur Grundlegung der Geisteswissenschaften. Leipzig und Berlin: B.G. Teubner, 1924: 139-240.

Gadamer, Hans-Georg. Truth and Method: the Basis of Philosophical Hermeneutics. Moscow: Progress, 1988.

Heidegger, Martin. History of the Concept of Time: Prolegomena. Tomsk: Vodoley, 1998. Hodges, Herbert Arthur. Philosophy of Wilhelm Dilthey. Routledge, 2003. 
Krotenko, Lidija. Psycholinguistics and the Search for Extraterrestrial Intelligence. Philosophy and Cosmology. Volume 19, 2017: 110-116.

Liashenko, Iryna. Historico-Philosophical issues in Wilhelm Dilthey's Hermeneutics: Methodological Aspect. Taras Shevchenko National University of Kyiv, 2008.

Makkreel, Rudolf. Wilhelm Dilthey. Stanford Encyclopedia of Philosophy, Aug 5, 2016. https://plato.stanford.edu/entries/dilthey/\#N190HistUndeHerm

Plotnikov, Nikolay. Life and History: Wilhelm Dilthey's Philosophic Program. Moscow: Dom intellektual'noy knigi, 2000.

Shpet, Gustav. History as a Problem of Logic. Wilhelm Dilthey. Two Texts about Wilhelm Dilthey. Moscow: Gnosis, 1995: 7-137.

Tappan, Mark. Interpretive Psychology: Stories, Circles, and Understanding Lived Experience. Journal of Social Issues, 53, Issue 4, 1997: 645-656. 